\title{
PLANEACIÓN ESTRATÉGICA EN \\ UNIVERSIDADES DEL CONSEJO DE RECTORES: EVIDENCIAS DEL PERIODO 2000-2005
}

\section{Introducción}

Las universidades chilenas han enfrentado un periodo de cambios profundos en los últimos 25 años, especialmente, a partir de la presente década. Las universidades del Consejo de Rectores que históricamente habían estado financiadas principalmente por el Estado a través de asignaciones directas de fondos de libre disponibilidad se vieron enfrentadas a decisiones estratégicas tales como ¿cuánto crecer?, ¿en qué áreas?, ¿en que regiones?, ¿cuánto invertir?, ¿qué actividades priorizar y cuáles dejar de hacer?, ¿cómo fijar el nivel de los aranceles?, ¿en qué segmento de estudiantes crecer? Asimismo, enfrentaron decisiones relacionadas con mayor eficiencia y efectividad en todas las funciones desempeñadas, como consecuencia de mercados más competitivos que exigen incrementos de calidad a precios razonables. En este nuevo contexto, aumentan las tensiones en el cumplimiento de objetivos institucionales, ya que las decisiones que privilegian un mayor desarrollo en la misión de la universidad, no necesariamente están asociadas a mayores ingresos para su financiamiento. Como consecuencia de estas tendencias en las políticas públicas y rol más protagónico del mercado en la educación superior, ¿están cambiando las prácticas de gestión en las universidades chilenas?, ¿en qué medida las universidades del Consejo de Rectores están respondiendo a estos nuevos desafíos de gestión institucional, a través de una profesionalización en su toma de decisiones?, ¿están las universidades utilizando instrumental técnico adecuado que les permita mejorar su gestión en este nuevo entorno más competitivo, cambiante y sujeto a mayor incertidumbre?, ¿se observan cambios en la gestión de recursos humanos, estructura organizacional, funcionamiento de cuerpos colegiados, utilización de instrumentos técnicos en la evaluación de proyectos y toma de decisiones, entre otros? 
Pese a los desafíos señalados, existe escasa evidencia directa sobre la profesionalización de la gestión universitaria en Chile. Una forma de aproximarnos a dicha evidencia, es investigar cómo se aborda el proceso de planeación estratégica en las universidades, lo cual tiene la ventaja de permitirnos evaluar el uso de diferentes instrumentos de planeación y gestión en los ámbitos de gobierno universitario, administración central, y ejecución de operaciones. Existen dos razones adicionales, para investigar sobre el uso de la planeación estratégica en las universidades del Consejo de Rectores.

En primer lugar, el Ministerio de Educación exige la aprobación del Plan Estratégico a nivel del más alto cuerpo colegiado en la institución, como requisito para postular a fondos concursables de nuevos recursos para proyectos MECESUP de enseñanza de pregrado, y postgrados ${ }^{1}$, y en los recientemente creados Convenios de Desempeño. ${ }^{2}$

La segunda razón, es que el proceso de acreditación institucional de la Comisión Nacional de Acreditación (CNAP) ${ }^{3}$, requiere un plan estratégico para evaluar la aplicación de políticas y mecanismos orientados a asegurar la calidad en, al menos, las áreas de pregrado y gestión institucional.

El objetivo de este artículo es investigar el proceso de formulación y uso de la planificación estratégica en una muestra seleccionada de universidades del Consejo de Rectores. Esta organizado del siguiente modo. La sección 2 describe la metodología del estudio; la sección 3 analiza los resultados; finalmente la sección 4 presenta las principales conclusiones.

1 Fondo de Innovación Académica, del Programa de Mejoramiento de la Calidad, y Equidad de la Educación Superior (MECESUP)

2 Los Convenios de Desempeño comenzarán a operar a partir del año 2007, previa postulación de proyectos durante el año 2006 en un plan piloto del Ministerio de Educación.

3 A partir del año 2006, con la aprobación de la Ley de Acreditación, se crea la Comisión Nacional de Acreditación, que reemplaza a la antigua CNAP, con nuevas funciones y reglamentos. Dado que este estudio se centra, principalmente, en el análisis de los planes estratégicos del periodo comprendido entre 1999-2000 y 2005-6, nos referiremos a la CNAP. 


\section{Metodología}

\subsection{Muestra de universidades.}

Se seleccionó una muestra de 8 universidades del Consejo de Rectores con el propósito de estudiar una diversidad de casos, bajo diferentes escenarios. La muestra permitió evaluar los instrumentos de planeación estratégica y de cuadro de mando integral en distintos contextos, tanto de condiciones internas, como de variables de entorno, las cuales condicionan la aplicación de estos instrumentos y sus resultados. Esta estrategia -similar a la metodología aplicada en el estudio de Anderson, D. et al (1999) en Australia, y con similares restricciones de acceso a información- permitió enriquecer y profundizar las conclusiones en el análisis comparado de universidades.

Las universidades consideradas en la muestra fueron las siguientes: Universidad de Chile (UCH), Pontificia Universidad Católica (PUC), Universidad de Concepción (UDEC), Universidad de Talca (UTA), Universidad de Playa Ancha (UPLA), Universidad Arturo Prat (UAP), Universidad de Los Lagos (ULA) y Universidad Tecnológica Metropolitana (UTEM).

El criterio para seleccionar estas universidades fue tener una muestra de instituciones que tuvieran en común recibir aportes fiscales directos del Estado, pero que se diferenciaran respecto de algunos aspectos, tales como:

Cuadro 1. Características de universidades de la muestra.

\begin{tabular}{l|l|l|l|l}
\hline Universidades & Propiedad & Orientación & $\begin{array}{l}\text { Acreditación } \\
\text { Institucional (años) }\end{array}$ & $\begin{array}{l}\text { Cuerpo colegiado de } \\
\text { gobierno }\end{array}$ \\
\hline U de Chile & Estatal & Investigación & 7 & $\begin{array}{l}\text { Senado y Consejo } \\
\text { Universitario }\end{array}$ \\
\hline PUC & Privada & Investigación & 7 & Consejo Superior \\
\hline U de Concepción & Privada & Investigación & 6 & Directorio \\
\hline U de Talca & Estatal & Docencia & 5 & Junta Directiva \\
\hline U de Playa Ancha & Estatal & Docencia & 2 & Junta Directiva \\
\hline UTEM & Estatal & Docencia & 0 & Consejo Superior \\
\hline
\end{tabular}




\begin{tabular}{l|l|l|l|l}
\hline U Arturo Prat & Estatal & Docencia & 0 & Junta Directiva \\
\hline U de Los Lagos & Estatal & Docencia & 0 & Consejo Superior. \\
\hline
\end{tabular}

Todas las universidades de la muestra cumplen funciones de docencia de pregrado, docencia de postgrado e investigación. La clasificación sólo pretende ilustrar diferencias en el énfasis de éstas funciones en relación a indicadores de desempeño nacional.

Otras diferencias: Universidades regionales, metropolitanas, estrategias de crecimiento, grados de centralización y descentralización en decisiones claves, tamaño, localización, entre otras, las cuales podrían explicar diferencias en prácticas de gestión

\subsection{Instrumentos y recolección de información}

La metodología comprendió diversas formas de recabar información para conocer el proceso de planeación estratégica, y el funcionamiento de la gestión institucional: i) revisión de documentos oficiales; ii) entrevistas a directivos; iii) visitas a casas centrales.

La primera fuente de información fue la revisión de documentos oficiales de la muestra de universidades, tales como el plan estratégico, presupuestos, documento de autoevaluación para la acreditación, dictamen de la CNAP sobre el resultado de la acreditación institucional.

En segundo lugar, el investigador principal entrevistó, separadamente, a autoridades y directivos de las universidades que han estado más vinculados con el proceso de planeación estratégica: rector o prorrector, vicerrectores y otros directivos. En total se realizaron 29 entrevistas, incluyendo 5 rectores, 2 prorrectores, 5 vicerrectores de asuntos académicos, 6 vicerrectores de asuntos económicos, 8 directores de planificación, análisis institucional o de estudios estratégicos. Respecto de los cuerpos colegiados se entrevistó 1 senador de la Universidad de Chile, 1 miembro del Directorio de la Universidad de Concepción y 1 miembro de la Junta Directiva 
de la Universidad Arturo Prat, cubriendo 3 formas de gobiernos universitarios. Dos limitaciones surgieron en la recopilación de información. Por un lado, las autoridades universitarias estuvieron muy bien dispuestas a entregar el plan estratégico, pero fueron cautos al exhibir documentos sobre planes operativos, cuando existían, no así respecto de programas de trabajo o de planes de desarrollo.

El periodo referencia para evaluar el proceso de planeación estratégica fue 1999/2000-2005/2006. El periodo de realización de esta investigación fue entre enero y junio de 2007, el cual coincidió con cambios de autoridades en algunas universidades y, en el caso de la Universidad de Chile, con la entrada en vigencia de la Ley que aprobó los nuevos estatutos, y dio origen al Senado Universitario.

Se optó por efectuar entrevistas en profundidad sobre la base de un esquema semiestructurado de 29 preguntas que cubren los tópicos de la investigación. Dada la naturaleza de las entrevistas, el tamaño reducido de la muestra, y las autoridades entrevistadas, el instrumento privilegió el análisis cualitativo del proceso de planeación estratégica, razón por la cual no se presenta una tabulación de los resultados. En síntesis, es un estudio exploratorio sobre el proceso de planeación estratégica en 8 universidades chilenas, siguiendo la metodología utilizada en el caso australiano, antes citado. Aun cuando la muestra incluye aproximadamente un tercio de las universidades del Consejo de Rectores, incluyendo las de mayor tamaño y complejidad del sistema, el análisis no necesariamente refleja la realidad de todo el sistema universitario.

El diseño de la encuesta semiestructurada comprendió 3 áreas: i) planeación; ii) implementación; iii) retroalimentación ${ }^{4}$.

4 Este instrumento se aplicó, en su totalidad a los directivos más vinculados al proceso de planeación estratégica en las universidades de la muestra (no necesariamente los mismos cargos en cada universidad). 


\section{Resultados}

\subsection{Consideraciones previas}

A continuación se caracteriza brevemente las fases de diseño y formulación, implementación, monitoreo y retroalimentación como factores críticos de la puesta en marcha de un plan estratégico en una universidad. El cuadro 2 ilustra la transición desde la etapa de aspiraciones hasta el plan estratégico institucional, con una etapa intermedia de orientaciones estratégicos destacando objetivos y lineamientos generales, pero no instrumentos, planes de acción, y presupuestos. La diferencia entre orientaciones y plan estratégico se explica, precisamente, por la mayor coherencia que muestra este último entre financiamiento y planes de acción, e integración de planes, entre otros.

- Plan Estratégico. Comprende 3 fases:

- Diseño y planeación. Surge a partir de un análisis FODA previo:

- Identifica las debilidades y amenazas a intervenir y las fortalezas y oportunidades a potenciar, y establece un plan de negocios.

- Incluye misión, visión, valores, objetivos generales y define un número reducido de prioridades institucionales, objetivos específicos, metas y rango de horizonte de tiempo para alcanzarlas.

- La etapa de planeación requiere definición de estándares actuales y proyectados, con el propósito de medir avances y emitir juicios evaluativos sobre éstos.

- Implementación. Define planes de acción con metas congruentes con el plan general, y estrategias de implementación.

- Asigna atribuciones y dota de instrumentos a los responsables de planes de acción que se designen para lograr las metas en los plazos previstos.

- Vincula presupuestos y recursos a los planes de acción.

- Las políticas pueden ser explícitas o implícitas, pero debe 
existir cierta documentación y formalización del sistema de incentivos que contribuiría a alcanzar los resultados.

- Construye capacidades de gestión institucional en diferentes niveles de la universidad, pero particularmente en el nivel de directivos y profesionales. El entrenamiento motivacional a directivos no es suficiente.

- Define e implementa una estrategia de comunicaciones orientada a informar la estrategia, motivar y persuadir, a la comunidad universitaria para lograr los objetivos y metas institucionales.

- Monitoreo, retroalimentación y rendición de cuenta. Esta fase es fundamental para identificar desviaciones y correcciones en los cursos de acción proyectados. Incluye:

- La definición y uso de indicadores de desempeño vinculados al plan estratégico, pero particularmente a los planes de acción.

- Medición de los avances, y evaluación de impacto de las medidas.

- Mecanismos efectivos de retroalimentación

- Rendición de cuentas internas a la comunidad, especialmente a los cuerpos colegiados que forman el gobierno universitario y a los sostenedores de la universidad. 
Cuadro 2. Hacia la construcción de un Plan Estratégico.

\begin{tabular}{|c|c|c|}
\hline Énfasis: & Énfasis: & Énfasis: \\
\hline $\begin{array}{l}\text { Misión y Visión, Valores. } \\
\text { Objetivos promocionales que } \\
\text { destacan la excelencia como valor } \\
\text { y objetivo a alcanzar. "Planes } \\
\text { estratégicos decorativos" }\end{array}$ & $\begin{array}{l}\text { Misión y Visión, Valores. } \\
\text { Objetivos generales por áreas } \\
\text { especificas. } \\
\text { Lineamientos de políticas y } \\
\text { algunas metas. } \\
\text { Marco para definir prioridades } \\
\text { institucionales } \\
\text { Mayor importancia de: } \\
\text { Consenso } \\
\text { Restricciones } \\
\text { Responsables } \\
\text { Plazos } \\
\text { Indicadores generales y aislados }\end{array}$ & $\begin{array}{l}\text { - Orientaciones Estratégicas } \\
\text { - Vínculo entre financiamiento y } \\
\text { planes operacionales } \\
\text { - Sistemas de incentivos con } \\
\text { consecuencias } \\
\text { - Plazos y responsables } \\
\text { - Indicadores y metas } \\
\text { - Monitoreo y retroalimentación } \\
\text { - Rendición de cuentas internas y } \\
\text { externas } \\
\text { Integración de planes y estrategias: } \\
\text { - Por áreas } \\
\text { - Por facultades } \\
\text { - Planes operativos y gestión } \\
\text { Enfoque sistemático y } \\
\text { comprometido con la excelencia } \\
\text { y el mejoramiento continuo, } \\
\text { totalmente incorporado en la } \\
\text { cultura organizacional. }\end{array}$ \\
\hline
\end{tabular}

Las universidades de la muestra presentan diferentes experiencias de planeación estratégica, en el periodo 1999/2000 -2005/2006, con elementos comunes en algunas etapas del proceso, y con diferencias que serán analizados más adelante. La influencia del Programa MECESUP en la formulación de planes estratégicos ha sido determinante, aunque tiende a predominar un enfoque de orientaciones institucionales. Dos observaciones en la concepción del proceso de planeación estratégica son destacables:

- Con excepción de la Universidad de Chile, todas las universidades declaran tener un plan estratégico institucional, en el periodo 1999/2000-2005/2006. Un factor determinante en la generalización de la planeación estratégica en estas universidades surgió a fines de los noventa. El Estado creó en 
1999 el Programa MECESUP 5 , dependiente del Ministerio de Educación, el cual exigió a las universidades que postularan a sus Fondos Concursables, la elaboración de un Plan Estratégico para un periodo de 5 años. Dicho plan constituiría la "carta de navegación" institucional de los proyectos que se adjudicarían financiamiento en las líneas de pregrado y postgrado.

La Universidad de Chile, es la única universidad que declara no haber formulado un plan estratégico en dicho periodo ya que optó por un enfoque de Orientaciones Estratégicas, el cual fue aceptado tanto en el Programa Mecesup del Ministerio de Educación para postular a los fondos concursables, como en la CNAP para efectos de la acreditación. Todas las demás universidades de la muestra declaran haber formulado un plan estratégico.

Lo positivo de la exigencia del Ministerio fue, en algunas universidades, iniciar el proceso de planeación o proveer incentivos para difundir esta práctica entre las universidades. Lo preocupante es que no al existir juicios evaluativos respecto del Plan Estratégico institucional, por parte de agencias externas, algunas universidades han actualizado los planes estratégicos más bien como un requisito para postular a los fondos públicos, más que por convicción de su efectividad.

- En la práctica, la mayoría de las universidades tiene orientaciones estratégicas, más que planes. Un análisis de los planes estratégicos institucionales en el periodo de referencia, comparado con la tipología de patrones de planeación descritos a partir del cuadro $\mathrm{N}^{\circ} 2$, permite concluir que la mayoría de las universidades no disponía de planes estratégicos de acuerdo a los estándares y fases de planeación, implementación, y monitoreo, antes indicada.

5 El Programa de Mejoramiento de la Calidad y Equidad en la Educación Superior, se creó el año 1998 aunque sus líneas de financiamiento a los proyectos comenzaron a funcionar a partir del año 1999 . 
El estado actual de los documentos parece reflejar mejor la etapa de Orientaciones Estratégicas, como veremos más adelante en un análisis más detallado. Asimismo, todas las universidades coinciden en que los documentos sobre planes estratégicos del quinquenio siguiente al periodo de referencia, esto es, 2005/2006-2010, muestran una mejoría respecto de los iniciales, como consecuencia de la experiencia adquirida. Como es obvio, estas apreciaciones sólo pueden ser consideradas como preliminares ya que algunas instituciones recién acababan de concluir la fase de diseño o planeación, sin entrar en la etapa de implementación ${ }^{6}$.

\subsection{Resultados en la fase de planeamiento}

\subsubsection{Misión, visión de largo plazo y el horizonte de planeación}

La misión de la universidad se refiere al mandato en su quehacer institucional y responde a preguntas tales como ¿Cuáles son los propósitos fundamentales de la institución?, ¿Cuál es el ámbito de su quehacer institucional, a quienes sirve y qué la distingue? Corresponde a una breve declaración oficial sobre lo que pretende en su quehacer institucional esencial.

La visión de la universidad, en cambio, destaca hacia donde se dirige la institución y donde desea estar en el largo plazo. Representa una prospección o exploración de escenarios futuros en que se desenvolverá la universidad. Se anticipa a los cambios del sistema de educación superior, y a los requerimientos institucionales que sean necesarios para mantener o acrecentar la competitividad institucional.

La revisión de la literatura de universidades de clase mundial entrega un patrón común sobre la declaración de misión y visión,

6 Recuérdese, además, que los planes estratégicos en el segundo periodo de referencia fueron formulados en la mayoría de las universidades ya sea por nuevas autoridades o antiguas autoridades iniciando nuevos periodos rectorales. 
con un predominio de ser breves en su descripción, acotadas y focalizadas en los fundamentos de su quehacer ${ }^{7}$. Por otro lado, la visión se establece de acuerdo con escenarios futuros, acompañados de una estrategia de implementación del plan institucional para lograr la posición deseada.

A partir del análisis de los documentos oficiales de las universidades del estudio, las conclusiones son las siguientes.

En primer lugar, no existe un patrón único en las declaraciones de misión y visión, aunque existe más coincidencia en la misión de universidad tradicional que en la visión.

En segundo lugar, las declaraciones de visión tienden a ser extensas, salvo excepciones, y se expresan más bien como desafíos, tareas pendientes en términos muy generales, o propuestas para avanzar, más que entregar una visión acerca de cómo se proyecta la universidad en el largo plazo, o el rumbo hacia donde se dirige para alcanzar la posición deseada.

En tercer lugar, el horizonte de planeación estratégica es variable, aunque tiende a predominar un periodo de 5 años. En general, se puede apreciar una tendencia a iniciar nuevos procesos de planeación con nuevos énfasis, e incluso ignorando avances previos, sin poner el acento en una visión de continuidad de mediano plazo, digamos 5 o 10 años, con planes quinquenales móviles ${ }^{8}$.

\subsubsection{Generación del proceso de planeación estratégica, y liderazgo del rector}

La mayor parte de las universidades comenzó el proceso de planeación estratégica con la presentación inicial de una propuesta del rector al

7 La Universidad de Harvard, por ejemplo, no tiene una declaración oficial de misión sobre todo su quehacer en la educación superior, sino que define su misión a nivel del pregrado en el college, y en ámbitos más específicos en que se desenvuelven sus organismos internos. Ver por ejemplo, What is Harvard's mission statement? http://www.harvard.edu/siteguide/ faqs/faql10.html

8 Algunas universidades de la muestra ya habían iniciado esta modalidad, o tenían pensado implementarla en el corto plazo. 
máximo cuerpo colegiado de la institución y al consejo académico. Dicha propuesta descansó en el programa que presentó el rector a la comunidad universitaria en el periodo de postulación a dicho cargo, o en diagnósticos previos efectuados en la institución.

En algunas visitas, en forma excepcional, fue posible conocer documentos internos que daban cuenta de debilidades y amenazas explícitas, aunque no es claro el conocimiento y utilidad de éstos informes al interior de la institución. El análisis FODA se reduce en algunas universidades a un extenso listado de percepciones cuya importancia relativa no es adecuadamente fundada, ni seguida de acciones efectivas en los planes de acción derivados del Plan Estratégico. Incluso en algunos casos, las debilidades y amenazas constituyen un listado de problemas interrelacionados sin distinguir causas de orden académico y de gestión, y sin identificar adecuadamente una relación causa-efecto. En otros casos, las oportunidades y fortalezas dan origen a expresiones optimistas sobre el futuro, que no están debidamente documentadas, o cuantificadas en ámbitos que son claves para la formulación de metas y recomendaciones de políticas.

La generación del proceso de planeación a partir de la propuesta del rector, ya sea a través de la base de programa como candidato o por medio de una propuesta preliminar interna para enriquecerla a través de una retroalimentación de la comunidad, no garantiza un liderazgo en la conducción del proceso. De acuerdo a Michael Shatttock (2003) el liderazgo académico en procesos de gestión institucional es una cualidad ambigua en las universidades, ya que no existe un patrón predominante, sino más bien depende de la cultura organizacional de la universidad, complejidad de ésta, naturaleza y calidad de su cuerpo académico, áreas disciplinarias, entre otras condiciones.

Más de la mitad de los vicerrectores y directivos de áreas, plantearon aprensiones respecto de las condiciones para ejercer un liderazgo académico, que persiga un proceso de transformaciones más acelerado que el actual en las universidades de la muestra. Influye

9 Shattock, M. (2003): Managing Succesful Universities. Bell \& Bain Ltd, Glasgow, page 91 
en esta apreciación que los rectores y decanos sean elegidos, y no siempre estén dispuestos a asumir costos políticos de liderar una visión de futuro, que signifique transformaciones y saltos cualitativos importantes en la posición de la universidad, junto a tensiones institucionales y restricciones de recursos para incentivar y financiar los cambios requeridos.

El liderazgo del rector, en la definición de prioridades institucionales, buenas prácticas de gobierno universitario, y en el sistema de incentivos de la organización, es un factor crítico de éxito en el plan estratégico de las universidades. Estas condiciones serán especialmente importantes en la etapa de implementación de planes de acción, y en la fase de administración del cambio organizacional. De otro modo, se corre el riesgo de que los cuerpos directivos y comunidad universitaria no se comprometan con las acciones requeridas.

\subsubsection{Gobernancia y rol de cuerpos colegiados de gobierno}

\subsubsection{Breve descripción del rol de los cuerpos colegiados}

De los cuerpos colegiados analizados en la investigación, el caso de la Universidad de Concepción es el más próximo al funcionamiento de una sociedad anónima o de responsabilidad limitada, con un Directorio que ejerce el rol de gobierno por mandato de la Asamblea de Socios de la Corporación, con obligación de rendir cuenta pública en una sesión extraordinaria anual, incluyendo la presentación de balances y estados de resultados auditados por una empresa de auditores independientes. No ocurre lo mismo con las Juntas Directivas, las cuales no tienen un mandato claro de una Asamblea o Socios que les otorgue poder para ejercerlo. En el periodo en estudio tampoco tenían la obligación de rendir cuenta pública, y de presentar balances y estados de resultados auditados ${ }^{10}$. El Consejo

10 A partir del año 2007 las universidades estatales están obligadas a publicar estados financieros, correspondientes al año 2006, auditados por empresas independientes, según la Ley 20.044 del año 2005. 
Universitario de la Universidad de Chile, tiene un carácter especial ya que al estar integrado por los decanos, éstos debieran responder ante la comunidad universitaria, por sus acciones; sin embargo, los decanos tienden a actuar como consejeros en algunas materias, pero también lo hacen como representantes de sus facultades, lo cual otorga a su representación cierto sesgo disciplinario y un rol más parcial que transversal, comparado con los integrantes del Directorio de la Universidad de Concepción, por ejemplo. Se espera que el Senado Universitario contribuya a resolver este problema.

Las diversas estructuras de gobierno universitario descritas para las universidades de la muestra, determinarían una gobernanza o prácticas de ejercicio del poder muy diferentes entre éstas, y jugarían un rol distinto en los procesos de planeación estratégica. ¿Cómo se genera la fase de planeación estratégica y monitoreo de sus resultados, a nivel de cada uno de estos cuerpos colegiados?, ¿participan realmente éstos, asumiendo responsabilidades, o es un proceso predominantemente aislado, delegado y focalizado en algunos directivos superiores?, iexiste un sistema de incentivos adecuado para que estos cuerpos colegiados ejerzan un rol protagónico en las directivas u orientaciones estratégicas?, ¿existen diferencias apreciables en el proceso de planeación estratégica en cuerpos colegiados en que participan académicos, comparados con aquellos en que estos últimos no tienen participación?, ¿importa, para estos objetivos, la presidencia del rector en los cuerpos colegiados?

\subsubsection{Principales conclusiones sobre el rol de los cuerpos} colegiados en los procesos de planeación estratégica.

El Plan Estratégico es aprobado por el cuerpo colegiado normativo de la Universidad. El protagonismo de este último y la profundidad de su participación en la definición de lineamientos, varía entre las universidades. En algunas, la retroalimentación es mínima, ya que este último delega prácticamente todo el proceso de planeación estratégica en el Rector y su equipo, limitándose solamente a la entrega de orientaciones o comentarios muy generales sin profundizar, salvo 
excepciones, en mecanismos aseguradores de calidad, eficiencia, costo-efectividad, entre otros. En estos casos, la etapa de planeación corresponde más bien a declaraciones de objetivos estratégicos amplios, y lineamientos de estrategias, sin asegurar consistencia en el uso de instrumentos que garanticen su logro.

La revisión de experiencias determinó las siguientes conclusiones:

- En todas las universidades, los cuerpos colegiados reconocen que la gestión de los aspectos académicos se realiza en las unidades académicas, y tienden a ser cautos en sus decisiones para no afectar la autonomía de éstas. Los rectores declaran que los cuerpos colegiados máximos de las instituciones procuran no intervenir en asuntos académicos directamente relacionados con las disciplinas que se cultivan en las unidades académicas. En todas las universidades con excepción de aquellas en que el cuerpo colegiado trata materias relacionadas con la normativa académica, como el Consejo Universitario de la Universidad de Chile y el Consejo Superior de la PUC, existe un Consejo Académico que se preocupa de materias de pregrado, postgrado e investigación; en algunos casos como cuerpo normativo, y en otros como instancia de carácter asesor del rector. El rector, en consecuencia, asume un rol fundamental en la coordinación de los cuerpos colegiados, equipo directivo y unidades académicas, para efectuar propuestas de objetivos y metas académicas en la fase de planeación.

- Los cuerpos colegiados máximos de las universidades tienden a asumir un rol más protagónico e ingerencia en aspectos patrimoniales, económico-financieros, y de gestión institucional. Sin embargo, la revisión de experiencias muestra que, en general, estos órganos descansan en las propuestas del rector y su equipo directivo más vinculado a estas materias. Esta es una situación razonable, en la medida que los cuerpos colegiados ejerzan sus atribuciones de monitoreo y retroalimentación permanente sobre los planes de acción que respaldan tales propuestas. Como veremos más adelante, esta situación tiende a ser un monitoreo débil, salvo excepciones. 
- Dos instancias fueron determinantes en la fase de planeación e implementación de las orientaciones estratégicas de la Universidad de Chile: Comisión de Asuntos Académicos, y Comisión de Economía. Esta última cubría algunas materias relacionadas con gestión institucional, así como la coordinación de acciones en el proceso de formulación de las Orientaciones Estratégicas aprobadas por el Consejo Universitario.

- En la Universidad de Concepción, el liderazgo del rector es fundamental para lograr un equilibrio de poderes y asegurar que cada cuerpo colegiado cumpla sus objetivos en el ámbito de sus atribuciones. Cuando algunas materias requieren considerar aspectos académicos y económicos, se realizan reuniones conjuntas, de Directorio y Consejo Académico, para resolver eventuales conflictos de objetivos. El rol del Directorio es importante no solamente en la fase de planeamiento y aprobación del Plan Estratégico, sino también en el monitoreo de acciones tendientes a cumplir sus objetivos. Estas acciones han sido fortalecidas por los compromisos financieros asumidos por la Universidad de Concepción debido a la emisión de un bono por un monto total de dos millones de UF, para financiamiento de largo plazo.

Además, de lo anterior, destacan tres antecedentes en el rol asumido por el Directorio de la Universidad de Concepción en el proceso de planeación estratégica: i) aprobación de estados de resultados proyectados, además de presupuestos; ii) estados financieros auditados por empresas externas; iii) rendición de cuentas del Directorio ante la Asamblea de Socios. ${ }^{11}$

- La Pontificia Universidad Católica de Chile presentaba experiencias de planeación estratégica desde comienzos de la década de los noventa, las cuales precedían la exigencia del Programa MECESUP

11 En prácticamente todas las universidades de la muestra los rectores dan cuenta de su gestión a la comunidad universitaria, sin embargo, ésta asume la modalidad de una presentación libre, sin requerir aprobación formal de la misma por parte del cuerpo colegiado, como es el caso de la U. de Concepción. 
de fines de esa década. Una vez al año el equipo directivo se reunía a analizar la ejecución de actividades de los últimos 12 meses y proyectar las actividades del año entrante, con visión de futuro. Esta fase de planeación fue incipiente en el sentido de consensuar una visión de conjunto respecto de los objetivos estratégicos que debía alcanzar la institución en los próximos años. Corresponde a un periodo de planeación flexible, que enfatizaba orientaciones estratégicas generales más que el logro de metas específicas surgidas de planes de acción u operativos. La principal ventaja de este periodo de planeación estratégica fue adquirir experiencia, y prácticas de planeación y gestión: introducir, conceptos tales como mayor efectividad por unidad monetaria invertida en la academia, medición y resultados de actividades, asumir el nuevo rol del Estado en materia de financiamiento, anticiparse a un escenario más competitivo, introducir prácticas exitosas de generación de ingresos compatibles con la misión de la Universidad, adaptar las prácticas de "tenure" en la academia al nuevo escenario que requería mayor renovación de personal académico, entre otras. En síntesis, la década previa a las exigencias de planes estratégicos efectuada por el Programa MECESUP, fue precedida en la PUC de un periodo de construcción de capacidades de gestión institucional, incipiente aunque sistemático, que logró anticiparse a los cambios que exigía el nuevo entorno de la educación superior.

- El proceso de generación de propuestas de planeación estratégica es similar en las otras universidades (UTA, UPLA, ULA, UAP, y UTEM), ya que la Junta Directiva o Consejo Superior delegan esta actividad en el Rector y su equipo. Son instituciones de tamaño más pequeño que las tres anteriores, considerando la cantidad de alumnos que ingresan vía PSU, y la cantidad de profesores medido en jornadas completas equivalente. Del mismo modo, todas realizan actividades de investigación y de postgrado, pero a bastante distancia de las universidades orientadas a la investigación. En este sentido, el proceso de planeación se concentra más en la actividad docente, con mayor importancia relativa en decisiones estratégicas respecto de generación de nuevas carreras y educación a distancia. En el caso de la Universidad Arturo 
Prat, la Universidad de Los Lagos y la Universidad Tecnológica Metropolitana ha sido importante también el énfasis en la creación de programas especiales de profesionales, nuevos programas de titulación e incluso nuevas sedes en regiones.

En los cuerpos colegiados de estas universidades, destaca la participación de algunos académicos muy destacados a nivel nacional, empresarios y profesionales de alta reputación en sus respectivos ámbitos de acción, designados como representantes del Presidente de la República. Aún así, tres de estas universidades no se acreditaron institucionalmente, y una la obtuvo por dos años. La Universidad de Talca, acreditada por 5 años, es la que figura en una posición expectante debido al mejoramiento de sus indicadores académicos durante la última década, junto con triplicar su participación en la distribución de aportes fiscales directos, en los últimos 15 años.

- ¿Cuál ha sido el rol de los representantes del Presidente de la República en los cuerpos colegiados de universidades estatales? En algunas universidades el rol de las Juntas Directivas ha sido activo en la retroalimentación de la propuesta de Plan Estratégico del Rector y su equipo. Asimismo, ha sido valiosa la composición variada y participación de sus integrantes que incluye, en general, la dimensión académica, empresarial, regional y política. Del mismo modo, existe evidencia de que los representantes del Presidente de la República actúan sobre la base de sus propias experiencias y juicios personales, sin constituir un vínculo gravitante, y efectivo, con las autoridades encargadas de las políticas públicas de educación superior. Más aún, el contacto con éstas es mínimo y, salvo excepciones, no constituyen una instancia de coordinación entre la política pública y las universidades.

Por otro lado, como veremos más adelante en la sección sobre monitoreo y rendición de cuentas, la información que reciben los integrantes de las Juntas Directivas responde más bien a criterios de contabilidad o administración pública, en lugar de criterios de gestión de organizaciones complejas y dinámicas insertas en un 
medio competitivo, como se caracteriza crecientemente el sistema de educación superior chileno. El problema no se reduce solamente a las Juntas Directivas, ya que abarca también los cuerpos colegiados de otras universidades de la muestra, pese a los esfuerzos que se han realizado en los últimos años, y que se profundizarán a partir de la exigencia legal a las universidades estatales de publicar estados financieros auditados por empresas auditoras externas. Más allá de la disponibilidad y calidad de la información, el problema de fondo es identificar las condiciones o factores críticos de éxito que deben satisfacer -desde el punto de vista de la planeación estratégica- los cuerpos colegiados de las universidades. Siendo instancias normativas, preocupadas de entregar las grandes definiciones institucionales desde una perspectiva de mediano y largo plazo, ¿convienen que exista un mínimo de integrantes autónomos con formación sólida en gestión universitaria que constituya una real masa crítica en estos cuerpos colegiados?, ¿es conveniente una mayor coordinación de acciones entre los representantes del Presidente de la República? Si bien el sistema de educación superior chileno descansa en una alta autonomía de gestión en las universidades que reciben aportes del Estado, podría ser deseable asegurar un mayor nivel de coordinación y/o articulación institucional como parte de una estrategia de cuerpos colegiados que tienen en común la presencia de representantes del Presidente de la República en las universidades estatales. ${ }^{12}$

- Cuando el rector preside el cuerpo colegiado de gobierno y un consejo académico, debe velar porque cada instancia asuma el rol que les corresponde de acuerdo a sus atribuciones, sin que interfieran con acciones en campos que no son de su competencia. Un problema adicional se presenta cuando el rector

12 Esto no significa una tendencia a uniformar el sistema, vuelta a universidades nacionales con sedes regionales, o perder autonomía académica en beneficio de un mayor poder del Estado en las decisiones, sino a aprovechar economías de coordinación entre instituciones de educación superior, y entre éstas y el sistema de educación media. Ver Millett, John (1984): Conflict in Higher Education: State Government Coordination versus Institutional Independence, Jossey-Bass Inc., Publishers, 1984; y Blake, P. (2006): Restructuring Relationships in Virginia: The Changing Compact between Higher Education Institutions and the State, Change: The Magazine of Higher Learning, v38 nl p26-33 Jan-Feb 2006 
está directamente involucrado en políticas y orientaciones de largo plazo, y en la gestión institucional. En este caso, pueden presentarse situaciones de difícil manejo en la gestión relacionados con la coyuntura de corto plazo, las cuales compete resolver al rector y su equipo a nivel ejecutivo, pudiendo entrar en conflicto con los objetivos estratégicos de largo plazo. La presidencia del Rector en ambos casos puede ser una ventaja si con su liderazgo busca acuerdos para compatibilizar ambos tipos de visiones y decisiones en cuerpos colegiados dotados de competencias, y que cumplen adecuadamente su rol en sus respectivos ámbitos de acción. Lograrlo, sin embargo, no es fácil, ya que pueden surgir tensiones entre ambos cuerpos colegiados al invadir el campo de decisiones más allá de sus atribuciones, confundiendo los planos normativos y ejecutivos. Existe abundante literatura sobre estos temas, y otros relacionados con la gobernanza, los cuales pueden contribuir a la formulación de propuestas para mejorar el funcionamiento de algunos cuerpos colegiados.

\subsection{Resultados en la fase de implementación del plan estratégico}

Asumiendo que la etapa de diseño está bien formulada, y los objetivos estratégicos han sido consensuados, cuentan con el respaldo político, y son realistas de alcanzar sobre la base de la aplicación de un conjunto de incentivos e instrumentos que lo respalden, entonces los siguientes factores pasan a ser determinantes en el éxito del plan:

- Definición explícita de las metas esperadas del plan estratégico.

- Formulación e implementación de planes de acción.

- Estrategias de descentralización y formalización adecuadas.

- Integración de estrategias de desarrollo académico y económico.

\subsubsection{Definición de metas explícitas}

Sólo dos universidades tenían documentos internos que explicitaban metas a alcanzar, pero su uso era reservado, e incluso no se conocían al interior de la institución, de modo que sus implicancias en la 
efectividad era cuestionable. La mayoría, sin embargo, reconoció que no tenía metas bien definidas. Diferentes razones explican esta omisión.

En primer lugar, en algunas universidades fue posible apreciar que no existían estudios técnicos previos para respaldar eventuales metas, ya que la información para construir algunos indicadores básicos era deficiente o tenía importantes distorsiones. La dificultad para avanzar en metas de calidad es mayor aún. Por ejemplo, todas las universidades pueden disponer de una estimación de tasas de retención por cohorte y a nivel agregado. Sin embargo, esto no significa que conozcan sus determinantes e importancia relativa de las variables que explican su nivel y evolución en el tiempo.

Una segunda explicación a la falta de metas es el reconocimiento implícito de evitar asumir compromisos que pudieran resultar difícil de lograr ya que el equipo de rectoría es el que asumiría los compromisos como administración central ${ }^{13}$, pero la mayoría de las metas de relevancia académica dependen de la gestión que se realice en las propias facultades, departamentos, carreras, o programas especiales. De modo que si no se tiene claridad respecto del manejo de los instrumentos, o esquema de incentivos efectivos disponibles y factibles de aplicar a nivel de la administración central para comprometer ciertas metas, existirá siempre alguna excusa para eludir parcialmente o totalmente este compromiso.

Una tercera explicación podría deberse a la aversión al riesgo de asumir determinados costos políticos los cuales, eventualmente, podrían surgir tras la implementación de ciertas medidas para alcanzar las metas ${ }^{14}$. En estos casos, si no existe el liderazgo requerido, algunos directivos preferirían no conocer los estudios técnicos que demostrarían ciertas debilidades institucionales difíciles de superar,

13 También asumiría los costos de equivocarse en caso de no lograr las metas.

14 Esta aversión al riesgo podría estar presente a nivel de rector, vicerrectores, o directivos en sus respectivos ámbitos de acción. 
sin asumir $\operatorname{costos}^{15}$. La racionalidad sería la siguiente, si se publican los indicadores actuales sobre ciertas variables, y se hacen públicas las causas que determinan el estado actual de resultados, entonces el equipo no puede eludir la responsabilidad de fijar metas, y aplicar medidas asumiendo los costos políticos que implica la corrección de situaciones detectadas en caso de debilidades y amenazas ${ }^{16}$. La situación inversa ocurre cuando el diagnóstico es suficientemente conocido en la comunidad universitaria, y está socializada la necesidad de asumir costos institucionales para corregir la situación. En este caso, lo más probable es que se logre el efecto contrario, ya que la fijación de metas sería bien recibida por la comunidad, y la administración central se fortalecería con la aplicación de un plan de acción con estos propósitos ${ }^{17}$.

En síntesis, los planes estratégicos de las universidades de la muestra no hacen explícitas sus metas en el sentido aquí descrito. Algunas lo incluyen en documentos internos reservados, que probablemente guían algunas acciones, pero su utilidad y efectividad es incierta. Lo más frecuentemente encontrado son objetivos generales y específicos tales como "mejoramiento de la calidad del pregrado", "fortalecimiento del postgrado", "aumento de la productividad en investigación", sin hacer referencias a cuantificación de metas. En los últimos años el Programa MECESUP ha estado enfatizando la necesidad de profundizar en la definición y uso de indicadores y metas; las

15 Se podría argumentar que esta es una situación límite. Sin embargo, existe una amplia literatura -basada en la teoría de agencias- que respalda la hipótesis de que los equipos directivos (administración central y facultades), evalúan estas opciones conocidas como riesgo moral en que los objetivos personales entran en conflicto con los institucionales. Esta situación se acentúa cuando las autoridades universitarias son elegidas y existe un contexto de asimetrías de información.

16 Por supuesto incluiría la situación que requiriera medidas para potenciar sus fortalezas y aprovechar las oportunidades, pero los costos políticos más inmediatos y visibles estarían asociados a la corrección de debilidades y amenazas.

17 Esta situación sería equivalente a un país que enfrenta una recesión interna generada por una perturbación internacional (que repercuten en una caída del precio o demanda de sus principales productos de exportación, por ejemplo), de modo que los habitantes de ese país son conscientes de que son más pobres que antes y que es conveniente para el país fijarse metas de corrección que incluyan recortes en el gasto de algunos programas sociales e inversión pública, aumento de desempleo, etc. En este caso, aumenta la probabilidad de que los costos políticos sean más que compensados por beneficios percibidos por la sociedad. 
universidades respondieron de inmediato, pero se desconoce el nivel de respaldo de tales propuestas ${ }^{18}$.

\subsubsection{Formulación de planes de acción}

Dado que en general las universidades tienden a no hacer explícitas metas exigentes y realistas, coherentes con la aplicación de instrumentos para lograrlas, los planes de acción, cuando existen, no necesariamente están documentados y oficialmente aprobados. Esta es una debilidad que atenta contra el alineamiento de esfuerzos y la efectividad del plan, ya que las interpretaciones sobre objetivos específicos, y efectos esperados suelen ser múltiples en diferentes momentos del tiempo, al no existir documentos oficiales, detallados y publicados.

Las universidades de la muestra tienden a no hacer explícitas sus políticas en todos los ámbitos, salvo las fundamentales, dejando margen para discrecionalidades en algunas áreas del quehacer institucional. Esta es una diferencia importante respecto del mundo universitario anglosajón que pone acento en hacer explícitas las políticas, normas y procedimientos ${ }^{19}$. La principal ventaja de esta última modalidad de gestión es que las reglas del juego son claras para todos los integrantes de la comunidad universitaria, en particular para los académicos, lo cual facilita la aplicación de instrumentos, monitorear avances y evaluar resultados ${ }^{20}$. La desventaja es que si las autoridades de la administración central, o de las unidades académicas, carecen de suficiente respaldo en sus decisiones, o quieren tener mayores márgenes de discrecionalidad en la gestión, las políticas explícitas le restan flexibilidad. Con todo, si bien no existen planes de

18 Los proyectos MECESUP incluyen metas para alcanzar sus objetivos específicos, sin embargo, no hay incentivos para plantear metas exigentes y el seguimiento del cumplimiento de objetivos académicos es débil. Existió la intención del Programa MECESUP de avanzar en el monitoreo de estos compromisos institucionales, pero el avance ha sido muy lento. El énfasis del seguimiento se concentra principalmente en las rendiciones financieras, y en los procesos de adquisiciones de los proyectos.

19 En realidad es una práctica generalizada a nivel de organizaciones, con y sin fines de lucro.

20 Particularmente en la políticas y reglamentos de evaluación y calificación académica. 
acción estrechamente vinculados a los objetivos del Plan Estratégico en la tradición anglosajona, se observa una implementación de medidas a través de acciones puntuales, reglamentos específicos, o por la vía de proyectos en el Presupuesto de la Universidad.

La principal debilidad detectada, sin embargo, son las implicancias de un plan de acción implícito. En general, no se designan responsables, dotados de instrumentos apropiados (incluyendo recursos), para cumplir metas específicas, en plazos acotados. Suponiendo que se lograra esta situación, no siempre existen los incentivos para cumplir y ser efectivos en el plan. La implicancia de este proceso es que no existen consecuencias para los eventuales responsables de un plan que no funciona, cuando este existe. Esta es una realidad reconocida por los directivos entrevistados en todas las universidades de la muestra, aunque la PUC presenta más avances en esta materia.

La situación no tendría mayores implicancias -desde la perspectiva de gestión- si en las facultades y otros organismos descentralizados existieran planes de acción alineados con el plan estratégico corporativo. Sin embargo, lo más probable es que los planes de acción de las facultades y organismos descentralizados, suponiendo que existen, tengan incentivos para estar más alineados con los objetivos del propio organismo que con aquellos del plan corporativo. Dos razones explicarían esta motivación. En primer lugar, existe evidencia casual de que la mayor lealtad de los académicos es con su disciplina, continuando con su entorno más inmediato (Departamento o Facultad), y luego con la Universidad. En segundo lugar, las unidades académicas generan ingresos, más allá de sus actividades regulares de pregrado e investigación, los cuales consideran como ingresos propios, o sobre cuyo destino tienen algo que decir. La mayoría de los directivos, coincidió en que esta tensión existe en universidades descentralizadas y centralizadas, estatales y privadas.

Si a nivel de la administración central existen las dificultades descritas para implementar planes, ¿cambia la situación en las 
facultades? ¿Tienen las facultades sus propios planes estratégicos?, ¿Tienen planes de acción alineados con sus planes estratégicos?

La visita a las universidades de la muestra permitió observar que sólo algunas facultades tienen planes de acción alineados con sus propias orientaciones y planes estratégicos. Otras, no consideran la planeación estratégica como instrumento que contribuya a la gestión, son escépticos a los beneficios de impulsarla, o prefieren referirse a proyectos de desarrollo, lo cual les permite establecer sus orientaciones de largo plazo, pero sin la presión de definir responsables, metas, plazos, fuentes de financiamiento, etc. Lo sorprendente fue que las facultades de Economía y Administración no se destacan precisamente por prácticas de planeación estratégica. Esto no significa, obviamente, que la gestión no se realice, pero podría constituir un antecedente en la dirección de privilegiar mayores grados de libertad y/o discrecionalidad en la gestión de estas unidades académicas.

\subsubsection{Descentralización y formalización de planes y políticas.}

3.3.3.1. Planes estratégicos y estrategias de descentralización y formalización

¿Se descentraliza la gestión en las unidades académicas?, ¿disponen éstas de herramientas para asumir la responsabilidad de sus decisiones?

Las entrevistas a directivos muestran que las universidades siguen diferentes prácticas en las políticas de centralización y descentralización, la cual es independiente del carácter de institución estatal o privada, grande o pequeña, orientada a la investigación o a la actividad docente. Una tensión que se advierte entre organismos de la administración central y unidades académicas, a partir de las entrevistas con los vicerrectores de asuntos económicos y a nivel de rectores o prorrectores es ¿Qué descentralizar?, y ¿Cuánto descentralizar? Un factor subyacente en la discusión, planteada por una de las autoridades entrevistadas es que "las unidades académicas preferirían una descentralización de los ingresos hacia ellos, y una 
centralización de los costos de decisiones, hacia la administración central; mientras estas últimas, preferirían lo opuesto", pese a la declaración de intenciones de trabajar en equipo.

Del mismo modo, la formalización de políticas, normas y procedimientos, expresada en documentos oficiales que definan las reglas del juego en la gestión institucional, significaría mayor transparencia en decisiones y procesos, además de claridad respecto del sistema de incentivos ${ }^{21}$. La contraparte es el riesgo de restar flexibilidad en la toma de algunas decisiones que requieran un tratamiento excepcional.

Las principales conclusiones en este ámbito son las siguientes.

- En 3 de las 8 universidades de la muestra el proceso de planeación se encuentra formalizado, documentado con respaldos, e implementado sobre bases regularmente programadas. Sin embargo, se advierte que en general no se realiza una evaluación documentada de las metas alcanzadas, y de los factores críticos que explique las desviaciones de los resultados del plan estratégico anterior, como una base a ser considerada en el nuevo plan.

- Las universidades formalizan algunas políticas, normas y procedimientos que consideran fundamentales en el quehacer institucional: creación de carreras y modificaciones de planes de estudios, normas que rigen la carrera académica y, en particular, el reglamento de calificación y evaluación académica. Como es obvio, utilidad y resultados de esta práctica difieren entre las instituciones.

- Los vicerrectores de asuntos económicos de las universidades estatales declaran que se preocupan, además, de cumplir con la formalidad de procedimientos regidos por la normativa que controla la Contraloría General de la República, aunque en

21 En este sentido, formalización de políticas, normas y procedimientos, no debe confundirse con burocracia. Esta última incluye acciones sin valor agregado desde la perspectiva de los usuarios. 
otras materias económico-financieras internas existiría menos formalización

- Las universidades, con excepción de la Universidad de Chile, tienden a ser centralizadas en sus presupuestos y asignación de recursos. La administración central capta aportes fiscales, recauda ingresos de matrícula, entre otros, y luego asigna. Conviene desatacar la experiencia de la Universidad de Chile ya que opera en forma más descentralizada y con políticas y normas conocidas y aprobadas, en la asignación de recursos internos. En particular, el $80 \%$ de la recaudación de los ingresos por concepto de aranceles de pregrado queda en las Facultades, y el 20\% restante contribuye al financiamiento del denominado Fondo General de la Universidad, al cual se suma el Aporte Fiscal Directo y el 50\% del Aporte Fiscal Indirecto, entre otros. Del mismo modo, las facultades retienen casi la totalidad de los ingresos generados en otras actividades, incluyendo postgrado, postítulos, venta de servicios, entre otras.

La contraparte, es que los Decanos asumen la responsabilidad por el equilibrio presupuestario de sus facultades, efectuando las propuestas de vacantes y reajuste de aranceles, y teniendo atribuciones para efectuar contrataciones de personal, otorgar asignaciones complementarias a su personal, e incluso financiar obras de infraestructura con los recursos generados. Esta es una situación de descentralización acompañada de formalización, que tiene como contraparte asumir responsabilidades por el equilibrio presupuestario y uso de los recursos. La responsabilidad por la gestión académica y sus resultados, depende, en cambio, de la cultura de calidad y masa crítica de cada unidad académica. Conviene destacar que esta estrategia contribuyó a que la Universidad de Chile lograra disminuir el déficit de su Fondo General observado en la década de los noventa, hasta alcanzar el equilibrio presupuestario el año 2005.

- La formalización de algunas decisiones económicas está vinculada también con la documentación y respaldo de estudios técnicos. En 4 de 8 universidades los directivos vinculados al área 
económica declararon que disponían (o habían efectuado en algún momento) estudios de costos de docencia por carrera, e incluso dos universidades dispondrían de costos en actividades prioritarias de investigación. Sin embargo, no se pudo constatar la existencia de estos estudios, la rigurosidad de la metodología empleada, ni su uso para efectos de políticas internas. Por otra parte, prácticamente todos los directivos coincidieron en que no disponían de estudios sobre subsidios cruzados entre actividades principales de la universidad, ni sobre precios de transferencia entre servicios prestados. Finalmente, en general, tiende a predominar un sistema de costeo por departamentos, aun cuando existió consenso sobre la necesidad de avanzar hacia un sistema de costeo basado en actividades. ${ }^{22}$

- Tiende a existir un divorcio entre los problemas de fondo de la universidad, cuando son identificados en la fase de diagnóstico, y el plan de acciones propuesto para resolverlos. Probablemente esta situación se explica porque las autoridades centrales de la universidad no siempre están en condiciones de decidir el curso de acciones correctivas, ya que manejan solamente algunos instrumentos de políticas, o no están dispuestas a anunciar estrategias de implementación. En el caso extremo "las autoridades, recomiendan, aconsejan, consultan, elaboran presupuestos, desarrollan planes, formulan guías de acción, reportan, supervisan, proponen iniciativas legales, asisten, se reúnen, discuten, capacitan, pero ¿acaso deciden?" (citado por Fanelli, A., 2005; 51 a partir de Clark (1992)).

22 Para una revisión de la aplicación de esta metodología y otras similares a nivel internacional ver, por ejemplo, las experiencia de los años noventa en Inglaterra, Joint Costing and Pricing Steering Group, http://www.jcpsg.ac.uk . En Estados Unidos destacan, los estudios del National Association of College and Business Officers, http://www.nacubo.org/ y del National Study of Instructional Costs and Productivity dirigido por University of Delaware, http://www.udel.edu/IR/cost/ 


\title{
3.3.3.2. Planeación estratégica en diferentes contextos de centralización y formalización de políticas
}

\author{
¿Cuánto de centralización - descentralización y cuánto de \\ formalización e informalidad en políticas implícitas? El cuadro 2 \\ muestra una tipología de universidades según niveles de centralización \\ y formalización de sus políticas, normas y procedimientos, adaptado \\ de Gareis, R. (1990)
}

\section{Cuadro 2a: Estrategias de centralización.}

\begin{tabular}{|c|c|}
\hline $\begin{array}{l}\text { Universidad centralizada con formalización de } \\
\text { políticas: }\end{array}$ & $\begin{array}{l}\text { Universidad centralizada con escasa formalidad de } \\
\text { políticas claves: }\end{array}$ \\
\hline $\begin{array}{l}\text { Corresponde a una situación de alta centralización } \\
\text { en sus decisiones a nivel del equipo directivo, unido } \\
\text { a prácticas en que predomina la formalización de } \\
\text { políticas, normas y procedimientos internos. Tanto } \\
\text { la centralización de decisiones como la formalización } \\
\text { explícitas de políticas no tienen por qué ser arbitrarias, } \\
\text { ni significar abusos de poder, aunque claramente } \\
\text { representa un escenario propio de universidades } \\
\text { que tienden a operar sobre la base de jerarquías en } \\
\text { su gestión. }\end{array}$ & $\begin{array}{l}\text { Corresponde a una universidad en que el centro de las } \\
\text { decisiones está determinado por una autoridad, grupo } \\
\text { pequeño de personas pertenecientes a un directorio, } \\
\text { equipo directivo o grupo influyente en la toma de } \\
\text { decisiones centralizadas. Hay una alta centralización } \\
\text { y control de las decisiones y una baja formalización de } \\
\text { las políticas, normas y procedimientos, lo cual podría } \\
\text { dar lugar a discrecionalidades, ya que el gobierno } \\
\text { de la universidad se rige por criterios y prácticas } \\
\text { muy flexibles las cuales, en caso extremo, se aplican } \\
\text { caso a caso. }\end{array}$ \\
\hline $\begin{array}{l}\text { Orientación de universidades. La Universidad de } \\
\text { Concepción está más próxima de este cuadrante, } \\
\text { básicamente por la forma de organización que asume } \\
\text { su Directorio como cuerpo colegiado y su interrelación } \\
\text { con el Consejo Académico, el liderazgo requerido del } \\
\text { rector para presidir y conducir ambas instancias; la } \\
\text { rendición de cuentas ante la Asamblea de Socios, los } \\
\text { balances y estados de resultados auditados, y las políticas } \\
\text { implementadas. La Pontificia Universidad Católica de } \\
\text { Chile también es más cercana a este cuadrante, por } \\
\text { las atribuciones del rector, las prácticas de planeación } \\
\text { estratégica perfeccionadas por casi dos décadas, y la } \\
\text { consistencia de sus políticas e instrumentos, con el } \\
\text { plan estratégico. Ambas universidades, sin embargo, no } \\
\text { tienen una alta formalización de sus políticas, normas } \\
\text { y procedimientos, aunque sí en áreas claves. }\end{array}$ & $\begin{array}{l}\text { Orientación de universidades. Las universidades más } \\
\text { próximas a este grupo son la Universidad de Los } \\
\text { Lagos, Universidad Tecnológica Metropolitana, la } \\
\text { Universidad Arturo Prat, Universidad de Talca y } \\
\text { Universidad de Playa Ancha. Son instituciones de } \\
\text { tamaño relativamente pequeño (en número de alumnos } \\
\text { que ingresan vía PSU), con un grado importante de } \\
\text { centralización en la decisiones económicas, número } \\
\text { reducido de facultades, institutos y centros de } \\
\text { investigación. La administración central se caracteriza } \\
\text { por un nivel menor de complejidad }{ }^{23} \text {, en relación a } \\
\text { las tres universidades más grandes y orientadas a la } \\
\text { investigación que forman parte de la muestra. Por otra } \\
\text { parte, tanto la UTEM como la Universidad de Los Lagos } \\
\text { tienen un Consejo Superior regido, por estatutos de } \\
\text { comienzos de los años noventa, que otorga atribuciones } \\
\text { al rector para ejercer una administración fuerte. }\end{array}$ \\
\hline
\end{tabular}

23 Lo cual facilita una administración relativamente flexible, que facilita la adopción de necesidades centralizadas en un contexto de baja formalización de políticas. 
Cuadro 2b: Estrategias de descentralización.

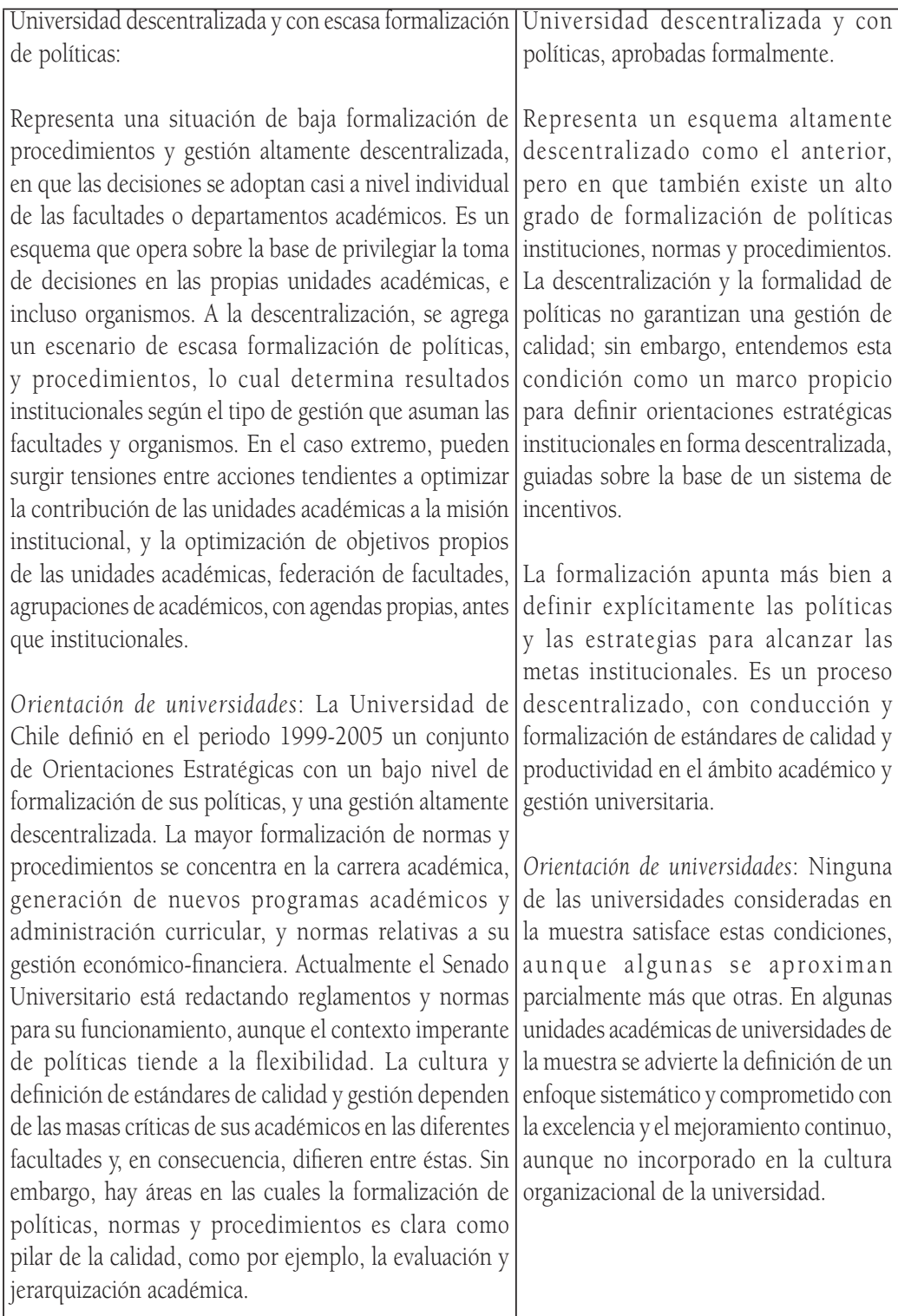

No existe una situación que defina las condiciones óptimas para seleccionar el grado de centralización y formalización de sus 
políticas, normas y procedimientos. Un buen o mal proceso de planeación estratégica puede observarse en cualquier cuadrante de combinación de políticas, dependiendo del contexto en que opere la universidad. Sin embargo, en un contexto competitivo la universidad puede definir y aplicar un esquema de reglas claras, estándares de gestión institucional y un sistema de incentivos, para inducir el comportamiento de las unidades académicas hacia el logro de metas institucionales, lo cual requiere más descentralización y formalización de políticas.

En otras palabras, descentralización no significa una pérdida de brújula o de la orientación institucional, o aceptar una gestión de dejar hacer y dejar pasar, sin rumbo, que no aproveche las sinergias al interior de la universidad. Por el contrario, es posible definir estándares como los señalados, en un contexto en que las decisiones se adoptan descentralizadamente, en los departamentos, programas y carreras, para enfrentar la competencia a través de los incentivos. En esta estrategia, los acuerdos sobre definiciones y prioridades institucionales son fundamentales. Estos no tienen por qué establecerse a través de la imposición de reglas en forma centralizada, sin considerar la cultura organizacional, pero tiene que existir una formalización de políticas y un sistema de incentivos que establezca explícitamente las prioridades. La persuasión tiene un límite, así como la motivación a través de declaraciones de intenciones.

Finalmente, todos los entrevistados coincidieron en que la construcción de capacidades de gestión institucional en todos los niveles de las universidades, es fundamental en una estrategia de descentralización. Algunos incluso plantearon que reconocían las ventajas de la descentralización, pero que no confiaban en las decisiones a nivel de unidades académicas, debido a debilidades en el sistema de incentivos con consecuencias (premios y castigos), así como las dudas que tenían respecto de la capacidad de gestión en las facultades y escuelas. 


\subsubsection{Integración de estrategias de desarrollo académico y económico.}

Suponiendo que la universidad ha logrado definir metas y consensuar el diseño e implementación de planes de acción, existirán tensiones producto de la incompatibilidad de alcanzar algunos objetivos. Una de las tensiones más frecuentes es entre cumplimiento de la declaración de misión, descrita en los planes estratégicos, y la generación de ingresos, la cual está más presente en instituciones de educación superior que han tenido, históricamente, una orientación de servicio público financiada mayoritariamente con fondos del Estado, y que han debido adaptarse a una situación actual en que su financiamiento responde principalmente a la generación de ingresos de matrículas y venta de servicios.

¿Cuáles son los mecanismos que disponen y utilizan estas universidades para integrar sus estrategias y aumentar las probabilidades de alcanzar sus objetivos y metas institucionales?, ¿existe evidencia indirecta de cómo actúan las universidades en la integración de estrategias en los ámbitos académicos y económico? Este no es un tema trivial, ya que en todas las universidades de la muestra tiende a predominar una asignación interna de recursos sobre la base de presupuestos históricos ${ }^{24}$, quedando un margen relativamente pequeño para inversiones o nuevos proyectos.

En algunas universidades la estrategia parece ser más cercana a un esquema que intenta mejorar la calidad y productividad académica de sus programas, sujeto a la restricción de presupuestos dada. En otras, el énfasis es más próximo a un esquema que intenta aumentar la generación de ingresos, sujeto a una restricción, más débil, de sostener un mínimo de calidad y pertinencia académica. Del mismo modo, se advierte una creciente preocupación por aspirar a donaciones, financiamiento de proyectos por la vía de agencias externas, particularmente del Programa MECESUP, entre otras.

24 Considerando los aportes institucionales o bases destinados a financiar remuneraciones y gastos operacionales. En la Universidad de Chile también se observa esta situación, aunque la recaudación de aranceles se descentraliza en un $80 \%$ a las facultades. 
En la revisión de experiencias de implementación de planes se observan dos debilidades adicionales. En primer lugar, en general, no se enfatiza la formulación de un plan de negocios ${ }^{25}$ que permita monitorear el avance en el cumplimiento de los objetivos específicos de los planes y la correspondiente ejecución de su programación financiera, para alcanzar los objetivos académicos de los programas. Sin embargo, la mayoría de las universidades de la muestra disponían de algún mecanismo de monitoreo económico de sus programas, especialmente después de haber enfrentado una situación preocupante de déficit en sus presupuestos, o de pérdidas en los estados financieros ${ }^{26}$. En segundo lugar, no se enfatizan fuentes de financiamiento por la vía de ganancias de eficiencia institucionales, esto es, liberación de recursos de actividades existentes a partir de rediseño de procesos que disminuyan costos y/o aumenten la productividad y generación de ingresos. Como lo expresó un vicerrector, la práctica parece ser "es más fácil aprobar o poner en marcha nuevos proyectos con recursos propios o autogenerados, que recortar o rediseñar programas académicos o procesos existentes". Esta es una diferencia importante respecto de la gestión en universidades de Estados Unidos o de algunas del Reino Unido, en que se crean nuevos programas y luego algunos desaparecen, ya sea porque fueron concebidos por un periodo acotado en el tiempo, o no se justifican dado un nuevo entorno ${ }^{27}$.

25 El plan de negocios es un instrumento recomendado para organizaciones con o sin fines de lucro, cualquiera sea su misión, ya que permite operacionalizar los objetivos estratégicos que se ha definido la organización en acciones concretas, identificando su financiamiento.

26 La Universidad de Concepción presenta una situación especial ya que mantiene un sistema de monitoreo a su Directorio, que destaca a nivel de universidades de la muestra, por las características en la conformación de este cuerpo colegiado.

27 Obviamente en todas las universidades de la muestra seguramente existen recortes de gastos con estas características, pero lo que se quiere ilustrar es que los niveles no son significativos, se concentran en el ámbito administrativo, y son poco frecuentes comparados con las universidades señaladas. Por ejemplo, el año 2005 Tulane University, disminuyó sus programas de doctorado desde 45 a 18 , eliminando 14 y fusionando otros. Además, disminuyó 5 programas de pregrado, y rediseñó el sistema de ingreso a la universidad, todo lo cual significó una reducción de contratos de 233 profesores. Ver: Seling, J., Fogg, P., Smallwood, S. (2005): "Tulane Slashes Departments and Lay Off Proffessors", Chronicle of Higher Education, December 16, 2005. 
3.4. Resultados de fase de monitoreo, retroalimentación, y rendición de cuentas

3.4.1. Investigación institucional e Indicadores de Desempeño

Las principales conclusiones de la visita a las universidades sobre este punto son las siguientes:

- Todas las universidades declaran tener un sistema de indicadores de desempeño en el ámbito académico y de gestión. Sin embargo, éste no está diseñado para monitoreo de planes estratégicos, sino para cumplir con requerimientos mínimos de rendición de cuenta pública: publicación de INDICE, Ministerio de Educación, o Anuario del Consejo de Rectores.

- Se realiza un seguimiento de algunos planes de acción, especialmente proyectos específicos, lo cual no constituye una práctica generalizada. En el 50\% de las universidades visitadas, la Vicerrectoría de Asuntos Económicos ejercía una acción más sistemática de seguimiento de proyectos, aunque desde la perspectiva económica-financiera. Estos corresponden predominantemente a proyectos nuevos que generan ingresos incrementales y, por tanto, constituyen una fuente de financiamiento para financiar contratación de académicos, realizar inversiones en infraestructura o equipamiento, entre otros usos. En otras palabras, el incentivo para efectuar el seguimiento es de orden económico, aunque sus resultados tengan implicancias de orden académico. Incluso en dos de las universidades visitadas, el visto bueno para la contratación de recursos humanos o inversión destinada a la academia lo otorga el vicerrector de asuntos económicos. Esto sugiere que los vicerrectores académicos disponen de menos instrumentos, comparados con sus pares de economía, para efectuar juicios evaluativos -con consecuencias- sobre el desempeño académico al interior de las universidades.

- Todas las universidades reconocen que los planes estratégicos 1999/2000 -2005/2006 no disponían de suficientes indicadores de desempeño definidos para cada objetivo estratégico clave o prioritario, aunque algunas tenían considerado incorporar esta 
práctica en el plan siguiente, para lo cual están trabajando.

- Respecto de las consecuencias del monitoreo, la mayoría de las universidades no efectúa un seguimiento de indicadores buscando las causas que determinan eventuales desviaciones significativas en el progreso de las actividades, y que tenga consecuencias en acciones de mejoramiento y retroalimentación sistemática. En dos de las universidades visitadas los directivos del área de planificación plantearon que lo hacían, sin embargo, el resto de los directivos de la misma universidad declaró lo contrario.

- En 6 de las 8 universidades visitadas, sus directivos declararon que no existió monitoreo del plan estratégico 1999/2000-2005/2006, o que éste era más bien pasivo, ya que el seguimiento se limitó a una aceptación pasiva de información de facultades y organismos, sin buscar mayores explicaciones de los resultados, y sin que sus resultados determinaran consecuencias. Sólo en dos casos respondieron que el seguimiento permitía investigar las causas de las desviaciones, en forma sistemática, aunque no generaban consecuencias.

\subsubsection{Información base para la formulación de un Balanced scorecard o Cuadro de Mando Integral (CMI)}

En 5 de las 8 universidades de la muestra los directivos de las áreas de planificación, análisis institucional, desarrollo y, en menor medida, económica-financiera, se mostraron interesados en desarrollar o perfeccionar sus sistemas de información para recolectar datos que les permitiera avanzar hacia la creación de un cuadro de mando integral en la institución. Las entrevistas permitieron detectar una alta motivación, y un firme propósito de implementarlo a la brevedad. Sin embargo, nuevamente la implementación y uso de la herramienta son lentos, y no forman parte de una estrategia institucional.

El cuadro de mando integral ha tenido una creciente aceptación en el mundo de las empresas, especialmente con fines de lucro, ya que permite disponer de un conjunto de indicadores claves, muy vinculados a sus operaciones, establecer metas en éstas, y luego 
seleccionar medidas para medir su avance en la dirección deseada. Es un instrumento adecuado para tener una visión integral, de lo que está sucediendo al interior, y exterior, de cada unidad o departamento, y medir su contribución al cumplimiento de la misión institucional. De este modo, es posible retroalimentar el sistema de incentivos para conducir la organización hacia las metas propuestas.

Existen experiencias de aplicación de esta herramienta en instituciones sin fines de lucro, y en universidades, aunque son relativamente escasas y acotadas a algunas áreas. La Universidad de Edimburgo es una referencia a nivel de una universidad compleja ${ }^{28}$, y Bailey, A.m Chow, Ch., Haddad, K. (1999) ${ }^{29}$ para una aplicación en el área de carreras vinculadas a la especialidad de negocios

El CMI no es simplemente un sistema de indicadores de desempeño, ya que es un enfoque integral, que interrelaciona causas y efectos en las siguientes perspectivas: Clientes o usuarios, procesos, innovación y aprendizaje, y financiera.

Las principales conclusiones de las entrevistas son las siguientes:

- En las universidades los académicos no están familiarizados con esta terminología, ya que tradicionalmente han considerado a los estudiantes como parte integrante de la comunidad universitaria en la relación enseñanza y aprendizaje. Esta percepción está cambiando y algunos directivos entrevistados en la muestra de universidades, se referían a los estudiantes como clientes. Sin embargo, más allá de la terminología, lo esencial es conocer ¿cuál es la percepción que tienen los usuarios, desde su perspectiva ${ }^{30}$ ? Lo importante en el CMI es la perspectiva del estudiante, y no la del profesor, o del director de escuela o carrera.

28 (www.planning.ed.ac.uk/SP2003-07/SP0307.htm

29 Bailey, A.m Chow, Ch., Haddad, K. (1999): "Continuous Improvements in Business Education: Insights From the For-Profit Sector and Business School Deans" Journal of Education for Business, January/February.

30 Este es un concepto amplio que incluye también a organismos del estado, empresas, y otras organizaciones sin fines de lucro, en sus demandas por investigación, consultorías y otros servicios, las cuales por razones de espacio no se analizan aquí. 
Este enfoque no está exento de discusión, dada la percepción histórica de algunos profesores que aún no aceptan instrumentos de retroalimentación, tales como encuestas de evaluación de los estudiantes sobre los cursos impartidos durante un semestre. En dos universidades de la muestra, algunos directivos plantearon la necesidad de realizar sistemáticamente encuestas a: estudiantes, egresados, docentes, y empleadores. Además, un directivo agregó que pensaba incorporar en forma regular encuestas de satisfacción de servicios. Sin embargo, la conclusión principal es que existe preocupación a nivel de directivos de las universidades de la muestra, sobre la necesidad de disponer de mediciones de satisfacción de los estudiantes sobre su formación, pero aún no existen estudios sistemáticos o, cuando existen, sus conclusiones no se utilizan regularmente en procesos de retroalimentación. La preocupación es mayor aún ya que la dimensión de usuarios en las universidades no sólo debiera considerar en qué medida la universidad satisface las expectativas de los estudiantes en el presente sino que, además, debiera anticiparse a las demandas de los estudiantes en los próximos años, considerando que su formación tarda al menos 5 o 6 años.

- Los directivos coincidieron en que las universidades se caracterizan por el trabajo individual y autónomo de sus académicos, departamentos, unidades académicas y facultades, en general ${ }^{31}$. Una consecuencia de este comportamiento es la dificultad para definir procesos transversales cuyo resultado depende de la contribución de más de una unidad académica. Todos los directivos declararon estar preocupados de definir procesos y generar este tipo de indicadores, tanto desde la perspectiva académica, como económica y de gestión institucional. Sin embargo, cuando existen, no se utilizan en forma generalizada. Esta es una limitante para el rediseño de procesos y se reconoce con una tarea pendiente.

31 Presente en todas las universidades, pero particularmente en las más grandes y orientadas a la investigación. 
- Algunos directivos declararon que los procesos de autoevaluación y de acreditación habían motivado a los académicos a estar más proclives a aceptar criterios de medición e indicadores de desempeño en algunos procesos académicos.

- Algunas unidades prestadoras de servicios, y más vinculadas con el sector productivo, están incorporando crecientemente normas de certificación en sus procesos internos, las cuales constituyen experiencias pilotos que esperan extender a otras áreas.

- Las conclusiones para las perspectivas de innovación y aprendizaje, así como perspectiva financiera, siguen un patrón de comportamiento similar a las conclusiones descritas para las perspectivas analizadas en esta sección.

\subsubsection{Rendición de cuenta interna y externa.}

Las universidades están más dispuestas a hacer anuncios sobre lo que quieren transmitir a la comunidad interna y externa, más que a publicar información y antecedentes que se aproximen a una rendición de cuenta pública. Algunos planes estratégicos están en la WEB, otros están impresos y distribuidos; en otros casos se publica incluso una sección en la WEB que entrega cifras sobre la universidad en un determinado periodo de tiempo. Por otra parte, prácticamente todos los rectores entregan una cuenta pública ya sea en ceremonias de inauguración del año académico, aniversario de la universidad, o en reuniones especialmente convocadas para este fin ${ }^{32}$. Aún cuando esta información constituye un avance, y aporta antecedentes sobre la marcha de la universidad, en ningún caso constituye información sistemática, con definiciones consistentes en el tiempo, y fuentes de información disponibles para ser corroboradas y consultadas ${ }^{33}$. En otras palabras, las universidades muestran más disposición a

32 Este es un práctica conveniente de mantener y muy útil. Es un caso análogo a la cuenta anual del Presidente de la República al Congreso Pleno el 21 de mayo; sin embargo, nadie esperaría que la marcha de las políticas públicas y el análisis de los indicadores se restringiera solamente a dicho discurso. Por el contrario, el país está incorporando crecientemente evaluación de impacto en sus programas, y está publicando cifras que permiten efectuar un monitoreo sistemático de la marcha del país.

33 En algunos casos se publica información oficial sin hacer referencias a las definiciones, ni métodos de cálculo, y sin citar fuentes de información. 
promocionar sus desafíos y avances de acuerdo a su interpretación, antes que a profundizar en una rendición de cuenta pública sistemática y susceptible de ser evaluada por la comunidad interna y externa ${ }^{34}$. En este contexto, los planes estratégicos institucionales se caracterizan más por enfatizar la fase de diagnóstico y los anuncios del punto de partida, pero pocas veces se conoce el avance y el cumplimiento de algunas metas intermedias. En parte, esto se debe a que los objetivos estratégicos se formulan de manera muy amplia y dispersa, sin precisar metas. Este es un comportamiento observado, en prácticamente todas las universidades de la muestra ${ }^{35}$.

Mención especial merece la rendición de cuenta al cuerpo colegiado de la universidad, como analizamos en la sección sobre los cuerpos de gobierno. Una pregunta central es ¿cómo el cuerpo directivo de la universidad informa a su cuerpo colegiado sobre el avance del plan estratégico y la marcha institucional? Todas las universidades entregan información, pero no necesariamente se cumple la función de monitoreo como se indicó en el punto anterior. Conviene recordar que hasta hace sólo seis meses atrás, las universidades estatales no publicaban balances y estados de resultados auditados por empresas externas. La información base para monitorear los aspectos económicos-financieros eran los presupuestos. Incluso una universidad aun formula sus presupuestos según las normas del Ministerio de Hacienda, válidas para otros propósitos, pero no desde la perspectiva de gestión. De este modo, la rendición de cuentas a través del Anuario del Consejo de Rectores podría mejorar significativamente si el objetivo fuese hacer seguimientos sobre la marcha de las universidades.

\footnotetext{
34 La información oficial publicada en organismos encargados de hacerlo, incluso presenta ciertas inconsistencias difíciles de explicar si no se dispone de suficientes antecedentes provistos por una rendición de cuentas sistemáticas.

35 Ver planes estratégicos en los respectivos sitios WEB de cada universidad.
} 


\section{Conclusiones}

Destacan cuatro conclusiones principales, del estudio:

- Las universidades incluidas en la muestra tienen planes estratégicos referenciales, los cuales destacan más por la formulación que por la implementación, monitoreo y retroalimentación. Estas últimas fases muestran debilidades en prácticamente todas las universidades visitadas. En la versión 2006-2010 de los planes estratégicos se advierte la intención de incluir metas e indicadores, aunque nuevamente no se explicitan instrumentos o planes de acción que respalden resultados esperados. Un factor clave en el desarrollo de los planes estratégicos ha sido la exigencia del Ministerio de Educación para postular a fondos concursables del Programa MECESUP. Sin embargo, mientras no exista una real profesionalización de la gestión al interior de las universidades, estos documentos serán más cercanos a orientaciones o lineamientos institucionales que a planes estratégicos.

- El liderazgo del rector, las prácticas de gobierno universitario y la gestión institucional, son factores críticos de éxito en la implementación de un plan estratégico. Nada se obtiene contratando un experto en planeación estratégica o de análisis institucional, si la universidad define objetivos, pero no tiene planes de acción bien definidos, con asignación de responsabilidades en su cumplimiento, metas y plazos. El sistema de incentivos (premios y castigos) en la organización es fundamental en el éxito del plan. Estas prácticas de gobierno y gestión universitaria no se observan, en general, en las instituciones de la muestra.

- Las universidades tienden a no dar importancia a la construcción de capacidades de gestión universitaria de los directivos en todos los niveles de la organización. Esta es una debilidad evidente para avanzar en la correcta aplicación de instrumentos del mundo de las empresas adaptados a las universidades, como ocurre en las universidades anglosajonas. Las prácticas de gobierno universitario revelan que los cuerpos colegiados aprueban las orientaciones estratégicas propuestas por el rector, pero tienden a no efectuar monitoreos exhaustivos en la etapa de implementación. 
- Una estrategia para avanzar en la implementación de planes estratégicos es la formalización de políticas (algunas claves como reglamento de evaluación y calificación académica) y la definición de estándares en calidad, productividad, y otros resultados esperados. Asimismo, las universidades deben definir prácticas de gobierno y gestión universitaria orientadas a la rendición de cuentas internas y externas, lo cual constituye una base para emitir juicios evaluativos, y adoptar medidas correctivas respecto de las desviaciones en la gestión en los diferentes niveles de la organización.

Finalmente, los antecedentes obtenidos en esta investigación permitirán efectuar, en una próxima publicación, una propuesta de construcción de capacidades de gestión universitaria, orientadas a la implementación de planes estratégicos, en instituciones con las características aquí analizadas. ${ }^{36}$

\section{Referencias bibliográficas}

Anderson, D., Johnson, R., Miligan, B. (1999) Strategic Planning in Australian Universities. Department of Education, Training and Youth Affairs. DEYTA No 6370. HERC99A.

Bailey, A.m Chow, Ch., Haddad, K. (1999): "Continuous Improvements in Business Education: Insights From the For-Profit Sector and Business School Deans" Journal of Education for Business, January/February.

Bensimon, E. M (2002): The Diversity Scorecard. A Learning Approach to Institutional Change.

Business Council of Australia (2003). Developing a framework for the financing and governance of Australian universities

Burke, J. and Minassians, H (2002). Performance Reporting: The preferred "No cost" Accountability Program The Sixth Annual Report. Rockefeller Institute.

Cáceres, C. (2007): "Plan Estratégico: ¿Brújula o mapa rutero?", Mimeo.

36 Cáceres, C. (2007): "Plan Estratégico: ¿Brújula o mapa rutero?", Mimeo. 
Dickeson, R. (1999): "Prioritizing Academic Programs Services: Reallocating Resources to Achieve Strategic Balance”. Jossey_Bass. San Francisco, USA.

Economist (September 2005): www.economist.com/surveys/displayStory. cfm?_id=4339960

Forest, J. J. and Altbach, P. G. (2006): "International Handbook of Higher Education". Part One: Global Themes and Contemporary Challenges". Springer. Netherlands.

Garcia de Fanelli, A. M (2005): "Universidad, Organización e Incentivos: Desafíos de la politica de financiamiento frente a la complejidad institucional". Miño y Dávila srl - Fundación OSDE, Buenos Aires.

Gareis, R. (1990): Handbook of Management by Projects, Manz

HEFCE (2006a): Review of performance indicators. Consultation to inform the review; (htpp://www.hefce.ac.uk/pubs/hefce/2006/06_34/).

HEFCE (2005): Leadership, Governance E Management in Universities, http:// www.hefce.ac.uk/lgm/lead/

Hoare, D. (1996): Review of management of higher education institutions, DEETYA, Australian Government Publishing Service, Canberra.

Keller, G. (2006): "Higher Education Management: Challenges and Strategies", in Forest, J. J. and Altbach, P. G. (2006): "International Handbook of Higher Education". Part One: Global Themes and Contemporary Challenges". Springer. Netherlands.

Lombardi, J., Craig, D., Capaldi, E., Gater, D. (2002): University Organization, Gobernance, and Competitiveness. The Top American Research Universities. An Annual Report from The Lombardi Program on Measuring University Performance. August 2002. (http://thecenter.ufl.edu/ UniversityOrganization.pdf)

Mintzberg, H. (1994): The rise and fall of strategic planning, Prentice Hall Internacional, Hemel Hempstead, UK.

Middaugh, M. (2004) Understanding Faculty Productivity: Standards and Benchmarks for Colleges and Universities. University of Delaware.

National Center for Education Statistics (2003): A Study of Higher Education Instructional Expernditures: The Delaware Study of Instructional Costs and Productivity. Research and Development Report. www.nces.ed.gov

Newby, H. "The management of change in higher education "Sir Howard Newby, 
Chief Executive of the Higher Education Funding Council for England http://www.tu-berlin.de/presse/ql/ql02_rede_newby.pdf).

NACUBO(a): Building Organizational Capacity in Higher Education (http://www. ncci-cu.org/Visitor/Documents/BOCDescription.pdf.)

NACUBO(b), http://www.nacubo.org/x1954.xml)

Porter, M. (1996): What is Strategy. Harvard Business Review (Nov-Dec).

Rae, I. D. (1997): Strategic Planning: is it war by other means?, Journal of Higher Education Policy and Management, 19, 2, pp. 185-94.

Ramsden, P (2000): "Learning to Lead in Higher Education". London: Routledge

Rodríguez, E. (2004): "La Toma de Decisiones Estratégicas: Una Perspectiva Integradora”. Ediciones Universidad de Tarapacá.

Shattock, M. (2003): Managing Succesful Universities. Bell \& Bain Ltd, Glasgow.

Sporn, B. (1999): Adaptive University Structures. London: Jessica Kingsley

Sporn, B. (2006): Governance and Administration: Organizational and Structural Trends", in Forest, J. J. and Altbach, P. G. (2006): "International Handbook of Higher Education". Part One: Global Themes and Contemporary Challenges". Springer. Netherlands.

Ruben, Brent D. (2001) "Excelence in Higher Education 2001-2002. A BaldrigeBased Guide to Organizational Assesment Planning, and Improvement". National Association of Colleges and Universities Business Officers".

Steiner, G. (1979): Strategic Planning, Free Press.

University of Illinois (2006): "Strategic Planning Framework". http://www. uillinois.edu/president/strategicplan/pdfs/University_Strategic_ Planning_Framework_2-16-06.pdf

Recibido: 20 de septiembre de 2007 Aceptado: 7 de noviembre de 2007 